\title{
Dead or Alive? Molecular life-dead distinction in human stool samples reveals significantly different composition of the microbial community
}

Alexandra Perras ${ }^{1,3,+}$, Kaisa Koskinen ${ }^{1,2,+^{*}}$, Maximilian Mora ${ }^{1}$, Michael Beck ${ }^{1,3 \dagger}$, Lisa Wink ${ }^{1}$ and Christine Moissl-Eichinger ${ }^{1,2}$

${ }^{1}$ Department of Internal Medicine, Medical University of Graz, Graz, Austria

${ }^{2}$ BioTechMed-Graz, Graz, Austria

${ }^{3}$ Department for Microbiology and Archaea Center, University of Regensburg, Regensburg, Germany

*Correspondence: Kaisa Koskinen

kaisa.koskinen@medunigraz.at

${ }^{\dagger}$ Present address:

Michael Beck, Roche Diagnostics GmbH, Penzberg, Germany

+equally contributed. 
bioRxiv preprint doi: https://doi.org/10.1101/343194; this version posted July 10,2018. The copyright holder for this preprint (which was not certified by peer review) is the author/funder, who has granted bioRxiv a license to display the preprint in perpetuity. It is made available under aCC-BY-NC 4.0 International license.

\begin{abstract}
The gut microbiome is strongly interwoven with human health. Conventional gut microbiome analysis generally involves 16S rRNA gene targeting next generation sequencing (NGS) of stool microbial communities, and correlation of results with clinical parameters. However, some microorganisms may not be alive at the time of sampling, and thus their impact on the human health is potentially less significant. As conventional NGS methods do not differentiate between viable and dead microbial components, retrieved results provide only limited information.
\end{abstract}

Propidium monoazide (PMA) is frequently used in food safety monitoring and other disciplines to discriminate living from dead cells. PMA binds to free DNA and masks it for subsequent procedures. In this article we show the impact of PMA on the results of $16 \mathrm{~S}$ rRNA gene-targeting NGS from human stool samples and validate the optimal applicable concentration to achieve a reliable detection of the living microbial communities.

Fresh stool samples were treated with a concentration series of zero to $300 \mu \mathrm{M}$ PMA, and were subsequently subjected to amplicon-based NGS. The results indicate that a substantial proportion of the human microbial community is not intact at the time of sampling. PMA treatment significantly reduced the diversity and richness of the sample depending on the concentration and impacted the relative abundance of certain important microorganisms (e.g. Akkermansia, Bacteroides). Overall, we found that a concentration of $100 \mu \mathrm{M}$ PMA was sufficient to quench signals from disrupted microbial cells.

The optimized protocol proposed here can be easily implemented in classical microbiome analyses, and helps to retrieve an improved and less blurry picture of the microbial community composition by excluding signals from background DNA.

Keywords: gut microbiome, life-dead distinction, propidium monoazide, next generation sequencing, microorganisms 
bioRxiv preprint doi: https://doi.org/10.1101/343194; this version posted July 10,2018 . The copyright holder for this preprint (which was not certified by peer review) is the author/funder, who has granted bioRxiv a license to display the preprint in perpetuity. It is made available under aCC-BY-NC 4.0 International license.

\section{Introduction}

The function of microbial communities depends on which community members are dead or alive, and the information about their status can be crucial for questions concerning microbial ecology or clinical relevance. For example a viable pathogenic bacterium poses a different risk to humans when present in pharmaceuticals or food as it might cause infection ${ }^{1}$, whereas contamination with dead microorganisms poses a potential risk for intoxication. Furthermore, clinical efficiency of fecal microbiota transplants depends on the living bacterial fraction of the preparation as only these bacteria could colonize the gut of the receiving patient ${ }^{2}$.

Several techniques have been developed to differentiate between live and dead microbes, focusing on three basic principles: To be considered alive, a microbial cell must be (1) intact, (2) able to reproduce, and (3) metabolically active (Emerson et al, 2017). The capability to reproduce can be ultimately assessed by cultivation-dependent methods, as, for the formation of colony forming units, cells have to divide and grow. However, only a comparatively small fraction of the Earth's microbiology can be cultivated using standard laboratory techniques at all $^{3,4}$. Metabolic activity can be estimated by metabolomics analyses or by analysing the content of (r)RNA, as it reflects the activity of microbial transcription; however, also dead cells can contain a considerable amount of RNA, blurring the results and conclusions 5 . Besides these vague approaches, the intactness of a cell is an unquestionable prerequisite for life, as life outside of a cell compartment does not exist.

One methodology to assess the intactness of a cell relies on the application of propidium monoazide (PMA). PMA masks free DNA and DNA of non-intact cells ${ }^{6}$, as it can pass disrupted cell walls and intercalate into the DNA double helix. Upon light exposure, PMA is covalently bound, blocking this DNA from subsequent PCR amplification ${ }^{6}$. When applied prior to DNA extraction, sequencing or qPCR, PMA treatment results in exclusive detection of the intact microbial fraction. By this principle, PMA treatment may also improve detection of rare community members as it helps to exclude background DNA from analysis ${ }^{7}$.

PMA has been applied in a wide variety of environmental and clinical microbiome studies, including research on the human microbiome ${ }^{7-9}$, indoor environments and built systems ${ }^{10,11}$ as well as on food products ${ }^{12-14}$. PMA is most typically used in standard PCR-based assays, but has also been successfully applied in combination with e.g. qPCR ${ }^{15-17}$, metagenomics ${ }^{18}$, fluorescence in situ hybridization (FISH) ${ }^{19}$, fluorescence microscopy ${ }^{20}$ and microarrays ${ }^{21}$. Another application aimed at the treatment of commercial PCR reagents to mask DNA contaminations (the "kitome"; ${ }^{12}$.

The original method foresees sample treatment with defined PMA concentration $(50 \mu \mathrm{M})$, incubation in the dark ( $5 \mathrm{~min}$, agitation) and a subsequent light exposure ( $2 \mathrm{~min}, 650 \mathrm{~W}$ lamp; ${ }^{22}$. However, the efficiency of PMA treatment is highly affected by density, homogeneity and turbidity of the handled sample ${ }^{23,24}$ and thus the original methodology might not be applicable to e.g. stool samples, although PMA treatment of faeces samples is as well a desired goal and has already been applied ${ }^{2,25,26}$. However, despite the high biomass and the complexity of faeces, optimal conditions of PMA treatment of faeces samples have not been elaborated yet. As a consequence, we wanted to know, whether an increased PMA concentration could compensate the problems of turbid and complex biosamples, such as faeces.

We herein analyze the effect of increasing PMA concentrations on the microbial community composition in human stool samples using amplicon-based next generation, with the goal to establish a guideline on how to reliably apply PMA in complex biosamples. 
bioRxiv preprint doi: https://doi org/10.1101/343194; this version posted July 10,2018 . The copyright holder for this preprint (which was not certified by peer review) is the author/funder, who has granted bioRxiv a license to display the preprint in perpetuity. It is made available under aCC-BY-NC 4.0 International license.

\section{Material and Methods}

\section{Samples and general organisation of experiments}

Fresh human feces was obtained from a healthy human individual and kept on ice until processing. The samples were diluted 1:10 (w/v) in DNA-free, sterile 1x phosphate buffered saline (PBS), and $500 \mu \mathrm{l}$ aliquots of the thoroughly mixed dilution were treated separately with increasing concentrations of PMA. We performed two subsequent experiments, experiment $\mathrm{A}$ and $\mathrm{B}$. In experiment $\mathrm{A}$, we studied the effects of PMA with 11 different concentrations between $0 \mu \mathrm{M}$ and $100 \mu \mathrm{M}$ PMA, and in experiment B we tested five different concentrations of PMA between $0 \mu \mathrm{M}$ and $300 \mu \mathrm{M}$. The fecal samples for experiment $\mathrm{A}$ and B were obtained from the same person, but at different time-points. The samples were sequenced in the same Illumina MiSeq run.

\section{PMA cross-linking and DNA isolation}

PMA was dissolved in PCR grade water to create a stock concentration of $20 \mathrm{mM}$ and stored at $-20^{\circ} \mathrm{C}$ in dark until usage. PMA was added directly to $500 \mu 1$ sample aliquots applying the following PMA concentrations in experiment A: $0 \mu \mathrm{M}, 10 \mu \mathrm{M}, 20 \mu \mathrm{M}, 30 \mu \mathrm{M}, 40 \mu \mathrm{M}, 50$ $\mu \mathrm{M}, 60 \mu \mathrm{M}, 70 \mu \mathrm{M}, 80 \mu \mathrm{M}, 90 \mu \mathrm{M}$ and $100 \mu \mathrm{M}$, and the following concentrations in experiment B: $0 \mu \mathrm{M}, 50 \mu \mathrm{M}, 100 \mu \mathrm{M}, 150 \mu \mathrm{M}$, and $300 \mu \mathrm{M}$. The samples were shaken on ice in dark for 10 minutes (IKA Rocker, $60 \mathrm{rpm}$ ) and light-exposed for 15 minutes in a standard PMA-Lite ${ }^{\mathrm{TM}}$ LED photolysis device with occasional shaking. After photo-induced crosslinking, DNA was extracted using the PowerSoil DNA extraction kit (Mo Bio Lab, Inc.) following the manufacturer's instructions. DNA concentrations were measured using the Qubit (Thermo Fisher Scientific) method and each assay was diluted to $10 \mathrm{ng} / \mu 1$ in PCR grade water as template for subsequent PCR reactions. All experiments were performed in triplicates. DNA extraction blank samples were used to control for the sterility of reagents and equipment.

\section{Library preparation for next generation sequencing (NGS)}

Variable region V4 of the $16 \mathrm{~S}$ rRNA gene was amplified with universal PCR primers $515 \mathrm{~F}$ (5'-GTGCCAGCMGCCGCGGTAA-3') and 806R (5'-GGACTACHVGGGTWTCTAAT-3') using TaKaRa Ex Taq polymerase (Clontech, Japan) ${ }^{27}$. The cycling conditions were: initial denaturation at $94{ }^{\circ} \mathrm{C}$ for $3 \mathrm{~min}$, followed by 35 cycles of denaturing at $94{ }^{\circ} \mathrm{C}$ for $45 \mathrm{~s}$, annealing at $60{ }^{\circ} \mathrm{C}$ for $60 \mathrm{~s}$, and elongation at $72{ }^{\circ} \mathrm{C}$ for $90 \mathrm{~s}$. The final elongation step lasted 10 min. Negative controls (no template) were included in PCR. Library preparation and sequencing were carried out at the Core Facility Molecular Biology at the Center for Medical Research, Graz, Austria. Briefly, DNA concentrations were normalized using a SequalPrep ${ }^{\mathrm{TM}}$ normalization plate (Invitrogen), and each sample was indexed with a unique barcode sequence (8 cycles index PCR). Pooled samples were purified with gel-cut procedure. Sequencing was conducted using Illumina MiSeq device. Sequence data were deposited in The European Nucleotide Archive (ENA) with study accession number PRJEB25855.

\section{Sequence data processing and analysis}

Raw sequence reads were preprocessed and filtered using the $\mathrm{R}$ package dada2 (version 1.4.0) according to the proposed processing pipeline ${ }^{28}$. Briefly, reads were demultiplexed, forward and reverse reads were quality filtered (min. score: 30 ), merged, and the dada2 core algorithm 
bioRxiv preprint doi: https://doi.org/10.1101/343194; this version posted July 10, 2018. The copyright holder for this preprint (which was not certified by peer review) is the author/funder, who has granted bioRxiv a license to display the preprint in perpetuity. It is made available under aCC-BY-NC 4.0 International license.

was applied. Taxonomic affiliations were assigned according to SILVA v123 database ${ }^{29}$. All ribosomal sequence variants (RSVs) which were present in negative controls were removed from the dataset; Normalization was performed by transformation to relative abundances. The downstream analyses were performed using R software package (version 1.0.136) ${ }^{30}$. Alpha and beta diversities were calculated using the R packages phyloseq (version 1.20.0) ${ }^{31}$ and vegan (version 2.4) ${ }^{32}$.

To compare microbial diversity in samples treated with different PMA concentrations, alpha diversity was calculated using the Shannon, Observed and Inverse Simpson index. Normal distribution was tested by the Shapiro-Wilk test, and statistical significance was tested either by Kruskal-Wallis (if not normally distributed) or ANOVA (if normally distributed). The Dunn's test was used as post-hoc test (Benjamin Hochberg correction).

Beta diversity analyses were performed to examine differences between microbial community profiles at different PMA concentrations. Principal coordinate analysis (PCoA) was performed to study the relationships and variation between samples. Statistical significance was tested using adonis (seed 1) and further confirmed by dispersion test (permutations: 999). Nonmetric multidimensional scaling (NMDS) was applied to visualise these differences. The data were also subjected to linear discriminant analysis effect size (LEfSe) analysis ${ }^{33}$ to determine specific microbial markers for PMA treatment of different concentrations.

\section{Results}

In order to determine the influence of increasing PMA concentration on the microbial community profile and diversity, we carried out two experiments: In experiment A, we compared the concentrations of $10 \mu \mathrm{M}$ to $100 \mu \mathrm{M}$ PMA (in $10 \mu \mathrm{M}$ steps) to non PMA treated samples and analysed the possible effects of PMA, and in experiment $\mathrm{B}$, we tested the concentrations of $50 \mu \mathrm{M}, 100 \mu \mathrm{M}, 150 \mu \mathrm{M}$ and $300 \mu \mathrm{M}$ PMA to confirm experiment $\mathrm{A}$. In both experiments we compared the PMA treated samples to non-treated samples.

Obtained sequence data were processed using dada ${ }^{28}$, and 1,597,041 sequence reads were obtained for experiment A (33 samples plus controls), and 716,611 sequence reads for experiment B (15 samples plus controls). After removing all taxa which were present in negative controls, 1,596,911 RSV counts (unique sequence reads) affiliated to 437 different taxa were left for experiment $\mathrm{A}$, and $715,808 \mathrm{RSV}$ counts (unique sequence reads) affiliated to 329 different taxa for experiment B. These data were analysed to show how the PMA treatment with different concentrations can influence alpha and beta diversities and the microbial community profile in specific taxonomic groups.

The analysis revealed a typical human gut microbial community profile within the studied samples. In experiment A we identified 16 microbial phyla, of which 13 were affiliated to Bacteria and 3 were affiliated to Archaea (Euryarchaeota, MSC (miscellaneous Crenarchaeotic Groups), and Thaumarchaeota). The most abundant phyla were Bacteroidetes (52.2 \% of all sequence reads), Firmicutes (37.7\%), and Proteobacteria (4.4\%). At genus level, the most abundant identified taxa were Bacteroides ( $37.7 \%$ of all sequence reads), Faecalibacterium (6\%), and Akkermansia (4\%).

In experiment $\mathrm{B}$, we identified 11 microbial phyla of which 9 were affiliated to Bacteria and 2 to Archaea (Euryarchaeaota and Thaumarchaeota). Again, the most abundant phyla were affiliated to Bacteroidetes (64.3\% of all sequence reads), Firmicutes $(29.1 \%)$, and Proteobacteria (5.2\%), while the most abundant genera were Bacteroides (42.9\%), a taxon 
bioRxiv preprint doi: https://doi.org/10.1101/343194; this version posted July 10,2018. The copyright holder for this preprint (which was not certified by peer review) is the author/funder, who has granted bioRxiv a license to display the preprint in perpetuity. It is made available under aCC-BY-NC 4.0 International license.

assigned to Bacteroidales family S24 (10.1\%), and Alistipes (5.4\%). The most abundant phyla identified in experiment A and experiment B are depicted in Figure 1.
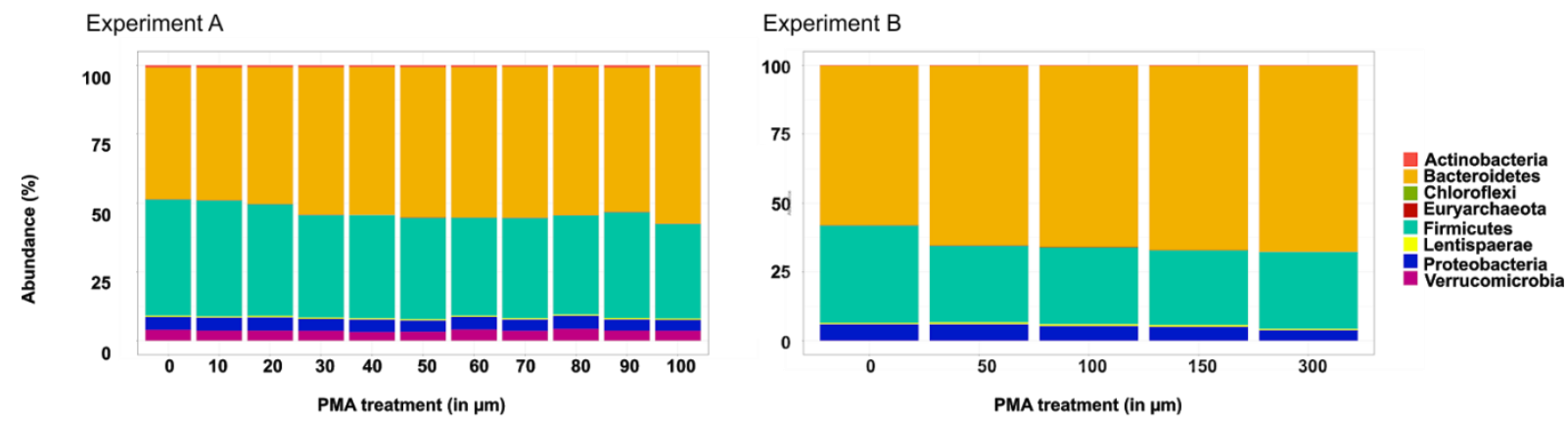

Figure 1. The most abundant phyla in experiment A and B. Majority of sequence reads were affiliated to Bacteroidetes and Firmicutes. Low abundant phyla $(>0.1 \%)$ are not included in the figure.

\section{PMA treatment significantly decreases microbial richness and diversity (alpha diversity)}

We studied how the PMA treatment might affect the alpha diversity of microbial communities in stool samples. The results show that alpha diversity (observed richness, Shannon and inverse Simpson indices) overall decreased with PMA treatment and that the effect was PMA concentration dependent. In experiment $A$ the observed richness significantly decreased (ANOVA, p=1.57e-06) with $30 \mu \mathrm{M}, 40 \mu \mathrm{M}$, and $50 \mu \mathrm{M}$ PMA concentrations when compared to non PMA treated control (all p-values were $<0.05$, Tukey's post-hoc test, confidence level 0.95). Additionally, the Shannon diversity index decreased with $100 \mu \mathrm{M}$ PMA treatment compared to untreated samples (ANOVA, $\mathrm{p}=0.00767$ ).

In experiment $\mathrm{B}$, a significant decrease in diversity was detected in the Shannon index when $300 \mu$ M PMA was used ( $\mathrm{p}=0.03121)$, and with inverse Simpson indices when $150 \mu$ M PMA $(\mathrm{p}=0.0498812)$ and $300 \mu \mathrm{M}$ PMA $(\mathrm{p}=0.0117023)$ was used, compared to $0 \mu \mathrm{M}$ PMA samples. Figure 2 summarizes the results, and highlights all statistically significant changes in alpha diversity upon PMA treatment. 


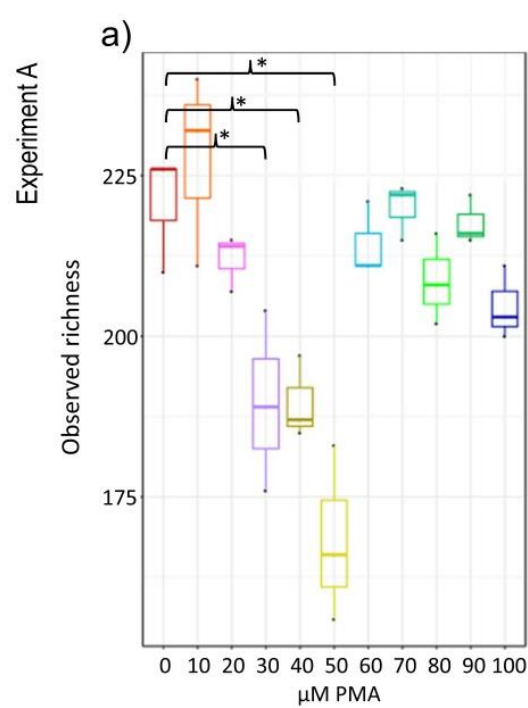

d)

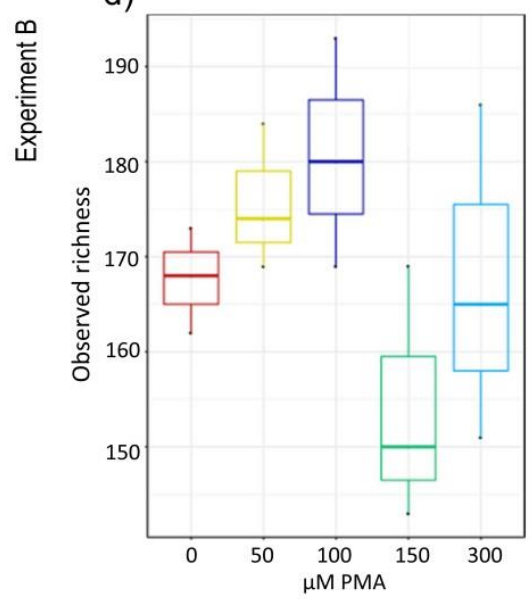

b)

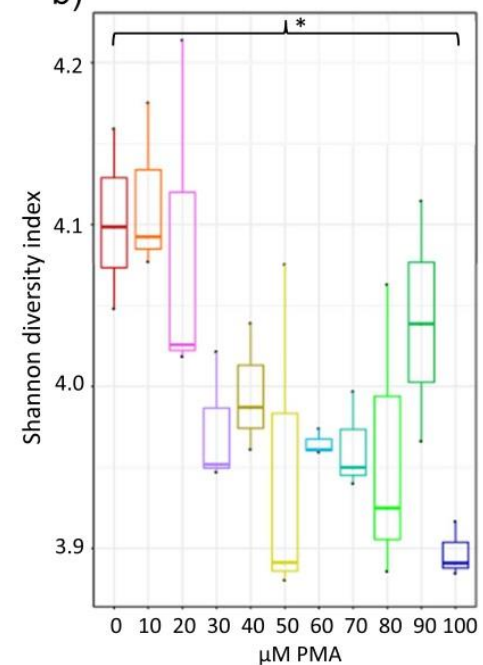

e)

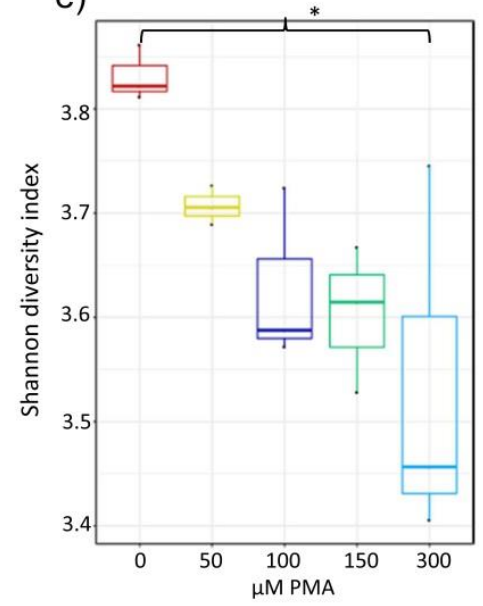

c)

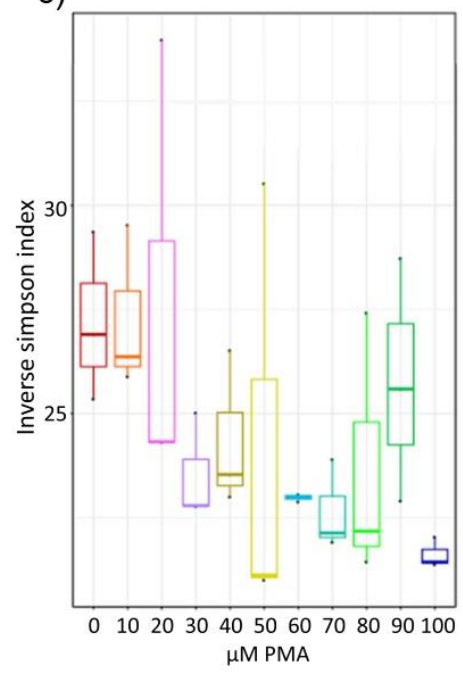

d)

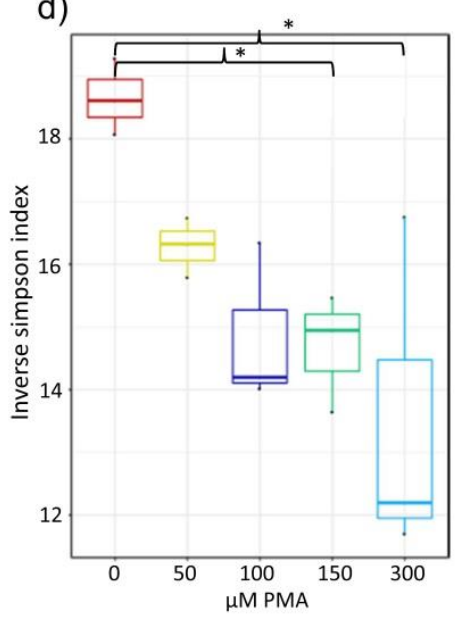

Figure 2. PMA treatment significantly decreases the detectable microbial diversity. In experiment A the observed richness (a) and Shannon diversity (b) significantly decreased with PMA treatment. In experiment B a significant decrease in diversity was detected by Shannon (e) and inverse Simpson (f) indices. Experiment A is pictured in the upper panel (a, b and c), and experiment B in the lower panel (d, e f). Statistically significant changes are marked with *.

\section{PMA treatment significantly alters the microbial community profile (beta diversity)}

We studied the effect of PMA treatment also on the overall microbial community profile. Therefore, we applied various beta diversity measures, including Bray-Curtis distance (unweighted) and tested for significant differences using Adonis, confirmed with a dispersion test. We visualised the beta community profile via nonmetric multidimensional scaling (NMDS).

The effect of PMA treatment was significant with respect to concentration. The results show that PMA treatment, particularly in higher concentrations, significantly shifted the microbial community profile (Figure 3, PCoA plots) (Adonis $\mathrm{p}<0.001$ ), from $0 \mu \mathrm{M}$ PMA to higher concentrations (Figure 3, NMDS). The significance was emphasized with a dispersion test (permutations: 999; both p-values $>0.8$ ). 


\section{Experiment $\mathrm{A}$}

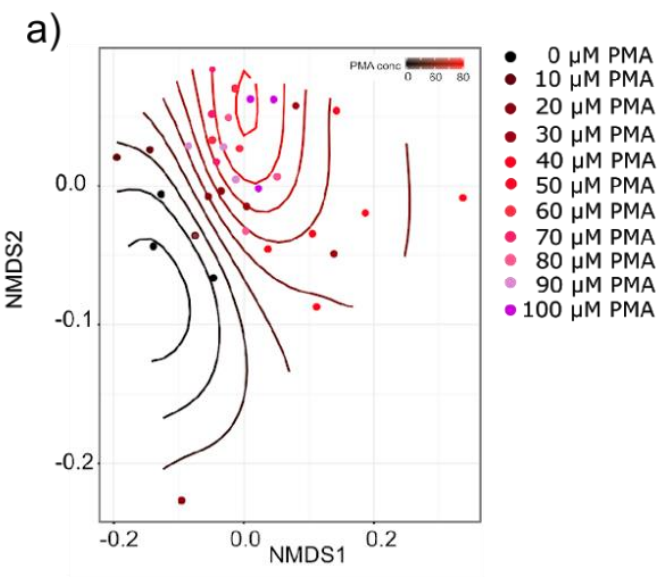

c)

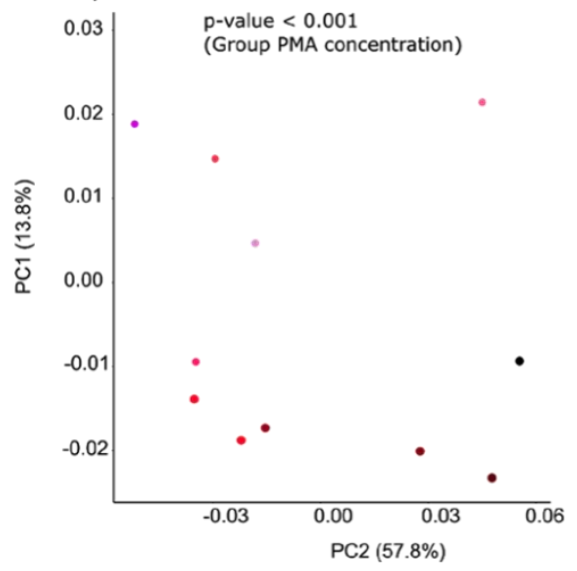

Experiment B

b)

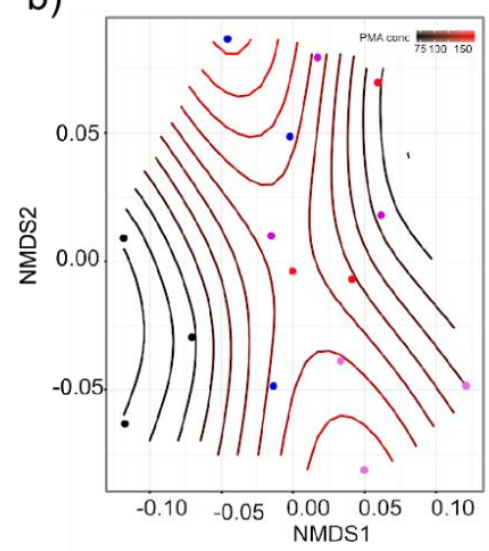

- $0 \mu \mathrm{M}$ PMA

- $50 \mu \mathrm{M}$ PMA

- $150 \mu \mathrm{M}$ PMA

- 300 нM PMA d)

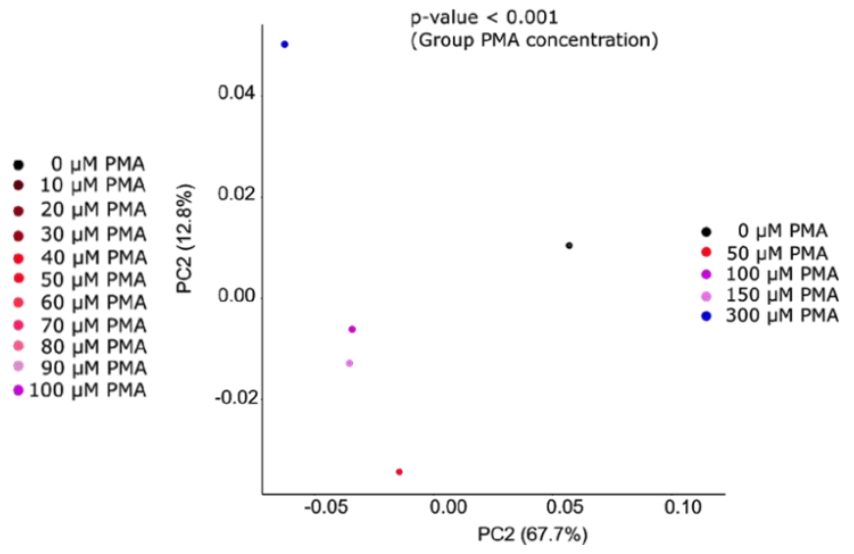

Figure 3. PMA treatment significantly alters the microbial community profile. Non-metric multidimensional scaling (NMDS) $(\mathrm{a}, \mathrm{b})$ visualisation presents a clear gradient from $0 \mu \mathrm{M}$ PMA to higher concentrations. Principal coordinate analyses (PCoA) (c,d) show that PMA treatment, particularly in higher concentrations, significantly shifted the microbial community profile (Adonis $\mathrm{p}<0.001$.) Experiment $\mathrm{A}$ is pictured in the left panel $(\mathrm{a}, \mathrm{c})$, and experiment $\mathrm{B}$ in the right panel $(b, e)$.

Additionally, we were interested in which taxa are responsible for the community shift. Using linear discriminant analysis effect size (LEfSe) algorithm we compared the median values of 100 most abundant microbial RSVs between samples without PMA treatment and different PMA concentrations. We were interested in particular if certain taxa are significantly less abundant in PMA treated samples, suggesting they are in non-intact (i.e. dead) state and consequently often overestimated regarding their relative abundance in microbiome studies, or if particular taxa are not affected by the treatment, or increase in relative abundance, indicating they are present in stool samples as intact, viable cells. 
bioRxiv preprint doi: https://doi org/10.1101/343194; this version posted July 10,2018. The copyright holder for this preprint (which was not certified by peer review) is the author/funder, who has granted bioRxiv a license to display the preprint in perpetuity. It is made available under aCC-BY-NC 4.0 International license.

In experiment A, the 100 most abundant RSVs represented 7 phyla, and in experiment B 6 phyla, which were the same as in experiment A except the phylum Verrucomicrobia, represented by one RSV of Akkermansia.

PMA treatment did not completely remove any taxon or RSV in experiment A, but in experiment B a total of $5 \mathrm{RSVs}$ were not detected after PMA treatment, indicating these taxa were in nonviable state (Supplementary Table 2). In both experiments, the majority of the 100 most abundant RSVs either increased or decreased statistically significant $(\mathrm{p}<0.05)$ in relative abundance at one or more PMA concentrations (experiment A 75\% RSVs changed significantly in their relative abundance, in experiment B 68\%).

All RSVs that changed significantly in experiment A or B are presented in Table 1, and information including all identified phyla and genera in both experiments can be found in Supplementary table 1 and Supplementary table 2.

In this study we show that the effect of PMA treatment might be indeed taxon specific (Table 1, Supplementary table 1, Supplementary table 2). The majority (57\% in experiment A / 53\% in experiment B) of RSVs belonging to the phylum Firmicutes had a lower relative abundance after PMA treatment (Supplementary table 1, Supplementary table 2). In both experiments, all RSVs of the genus Faecalibacterium, and most RSVs in the families Lachnospiraceae and Ruminococcaceae were significantly reduced by PMA treatment, suggesting their relative abundance can be overestimated when nonviable cells are not masked (Table 1).

In contrast to Firmicutes, relative abundance of the phylum Bacteroidetes increased $(69 \%$ of RSVs in experiment A / 68\% of RSVs in experiment B). The majority of RSVs belonging to the genera Alistipes ( $75 \%$ in experiment A / $100 \%$ in experiment B), Bacteroides $(71 \%$ in experiment A / 77\% in experiment B), and Parabacteroides (50\% in experiment A / $100 \%$ in experiment B) show significant increase in relative abundance after PMA treatment (Table 1, Supplementary table 1, Supplementary table 2). Additionally, the phylum Lentisphaerae (genus Victivallis) increased significantly in relative abundance in both experiments.

Change in relative abundance of Bifidobacterium (Actinobacteria) and Akkermansia (Verrucomicrobia) upon PMA treatment was only detectable in experiment A as these taxa were not found in experiment B. The relative abundance of Bifidobacterium decreased significantly when the sample was treated with $60 \mu \mathrm{M}$ PMA or more; the relative abundance of Akkermansia it reduced significantly when the sample was subjected to at least $30 \mu \mathrm{M}$ PMA treatment.

The results suggest that if PMA treatment is not applied, the relative abundance or relevance of these bacteria, which are known to carry beneficial properties for human health, could be overestimated. 
Table 1. Summary of significantly changed RSVs in experiments A and B (100 most abundant RSVs; LEfSe). RSVs which increased ( $\uparrow)$ or decreased $(\downarrow)$ in relative abundance (concordant results for all concentrations) with PMA treatment are listed. Number of RSVs for each genus are given in brackets if there were more than one. One RSV which was present (Parabacteroides) but did not change significantly in with PMA treatment (Experiment A) is marked with -. RSVs which were not present in one of the experiments are empty. Numbers after genus information depicts the number of RSVs giving similar result. Full information on the 100 most abundant identified RSVs and results including PMA concentrations is available in Supplementary Table 1 and Supplementary Table 2.

\begin{tabular}{|c|c|c|c|c|c|}
\hline Genus & $\begin{array}{c}\text { Exp. } \\
\text { A }\end{array}$ & $\begin{array}{c}\text { Exp. } \\
\text { B }\end{array}$ & Genus & $\begin{array}{c}\text { Exp. } \\
\text { A }\end{array}$ & $\begin{array}{c}\text { Exp. } \\
\text { B }\end{array}$ \\
\hline Actinobacteria & & & Firmicutes & & \\
\hline Bifidobacterium (2) & $\downarrow$ & & Romboutsia & $\uparrow$ & $\uparrow$ \\
\hline Bacteroidetes & & & Roseburia & $\downarrow$ & $\uparrow$ \\
\hline Alistipes (3) & $\uparrow$ & $\uparrow$ & Roseburia & & $\downarrow$ \\
\hline Alistipes & & $\uparrow$ & Ruminiclostridium_6 & $\downarrow$ & $\uparrow$ \\
\hline Bacteroides (9) & $\uparrow$ & $\uparrow$ & Ruminiclostridium_6 & $\downarrow$ & $\downarrow$ \\
\hline Bacteroides & & $\uparrow$ & Pseudobutyrivibrio & $\downarrow$ & $\downarrow$ \\
\hline Barnesiella & $\uparrow$ & $\uparrow$ & Ruminococcaceae_UCG-002 & $\downarrow$ & $\downarrow$ \\
\hline Odoribacter & $\uparrow$ & & Ruminococcaceae_UCG-002 (3) & $\downarrow$ & \\
\hline Parabacteroides & $\uparrow$ & $\uparrow$ & Ruminococcaceae_UCG-005 (2) & $\uparrow$ & \\
\hline Parabacteroides & - & $\uparrow$ & Ruminococcaceae_UCG-005 & $\downarrow$ & \\
\hline NA (Bacteroidetes) (2) & $\uparrow$ & $\uparrow$ & Ruminococcaceae_UCG-010 & $\downarrow$ & $\downarrow$ \\
\hline NA (Bacteroidetes) & $\downarrow$ & & Ruminococcaceae_UCG-010 & $\uparrow$ & \\
\hline Firmicutes & & & Ruminococcaceae_UCG-013 & $\downarrow$ & $\downarrow$ \\
\hline Anaerostipes & $\downarrow$ & & Ruminococcaceae_UCG_014 (3) & & $\downarrow$ \\
\hline Anaerotruncus & $\uparrow$ & $\uparrow$ & Ruminococcus_1 & $\downarrow$ & $\uparrow$ \\
\hline Blautia & $\downarrow$ & $\downarrow$ & Ruminococcus_2 & & $\uparrow$ \\
\hline Blautia (2) & $\uparrow$ & $\downarrow$ & Subdoligranulum & $\downarrow$ & $\downarrow$ \\
\hline Blautia & & $\downarrow$ & Subdoligranulum & $\uparrow$ & $\downarrow$ \\
\hline Coprococcus_2 & $\downarrow$ & $\downarrow$ & Terrisporobacter & & $\downarrow$ \\
\hline Coprococcus_2 & & $\downarrow$ & \begin{tabular}{|l|l} 
Eubacterium]_coprostanoligenes_group \\
\end{tabular} & $\uparrow$ & \\
\hline Defluviitaleaceae_UCG_011 & & $\downarrow$ & [Eubacterium]_coprostanoligenes_group & $\downarrow$ & \\
\hline Faecalibacterium (4) & $\downarrow$ & $\downarrow$ & [Eubacterium]_ruminantium_group & $\downarrow$ & $\uparrow$ \\
\hline Fusicatenibacter & $\downarrow$ & $\downarrow$ & [Eubacterium]_ventriosum_group & $\downarrow$ & $\downarrow$ \\
\hline Incertae Sedis (Firmicutes) (3) & $\downarrow$ & $\downarrow$ & NA (Firmicutes) (2) & $\downarrow$ & \\
\hline Intestinibacter & $\downarrow$ & $\downarrow$ & Lentisphaerae & & \\
\hline Lachnoclostridium & $\downarrow$ & $\downarrow$ & Victivallis & $\uparrow$ & $\uparrow$ \\
\hline Lachnospira & & $\downarrow$ & Proteobacteria & & \\
\hline Lachnospira & $\uparrow$ & $\uparrow$ & Escherichia_Shigella & $\downarrow$ & $\downarrow$ \\
\hline Lachnospiraceae_ND3007_group & $\downarrow$ & $\downarrow$ & Sutterella & $\uparrow$ & $\uparrow$ \\
\hline Lachnospiraceae_NK4A136_group & $\downarrow$ & $\downarrow$ & Thalassospira & $\downarrow$ & $\downarrow$ \\
\hline Lachnospiraceae_UCG-003 & $\downarrow$ & $\downarrow$ & Tenericutes & & \\
\hline Lachnospiraceae_UCG-004 & $\downarrow$ & $\downarrow$ & NA (Tenericutes) & $\uparrow$ & \\
\hline Lachnospiraceae_UCG-004 & & $\downarrow$ & Verrucomicrobia & & \\
\hline Phascolarctobacterium & $\downarrow$ & $\downarrow$ & Akkermansia & $\downarrow$ & \\
\hline
\end{tabular}

Notably, in both experiments we identified four proteobacterial RSVs (Bilophila, Escherichia/Shigella, Sutterella, and Thalassospira), and in both experiments Escherichia/Shigella and Thalassospira were relatively decreased and Sutterella was increased with PMA treatment. In both experiments, the abundance of genus Bilophila did not 
bioRxiv preprint doi: https://doi.org/10.1101/343194; this version posted July 10, 2018. The copyright holder for this preprint (which was not certified by peer review) is the author/funder, who has granted bioRxiv a license to display the preprint in perpetuity. It is made available under aCC-BY-NC 4.0 International license.

alter. These results indicate that Escherichia/Shigella and Thalassospira are found in gut also in nonviable state and their abundance can be overemphasized.

\section{Concentration of $100 \mu \mathrm{M}$ PMA is sufficient to discriminate intact and dead cells in stool samples}

We were interested in the optimal concentration of PMA needed to mask the dead cells in stool samples, and studied with which concentration the significant changes in relative abundance are visible at RSV level. Out of 100 most abundant RSVs in experiment A, 75 RSVs changed significantly with PMA treatment; the change occurred only in 6 RSVs with $10 \mu \mathrm{M}$ PMA concentration. In 14 RSVs (19\%) the change was significant already with $20 \mu \mathrm{M}$ PMA, 30 RSVs with $30 \mu \mathrm{M}$ PMA, 38 RSVs with $40 \mu \mathrm{M}$ PMA, 26 RSVs with $50 \mu \mathrm{M}$ PMA, 45 RSVs with $60 \mu \mathrm{M}$ PMA, 43 RSVs with $70 \mu \mathrm{M}$ PMA, 31 RSVs with $80 \mu \mathrm{M}$ PMA, 45 with RSVs $90 \mu \mathrm{M}$ PMA, $52 \mathrm{RSVs} 100 \mu \mathrm{M}$, suggesting that in this experiment, $100 \mu \mathrm{M}$ of tested concentrations was most efficient in masking the nonviable cells. A graphical overview on experiment $\mathrm{A}$ is given in Figure 4.
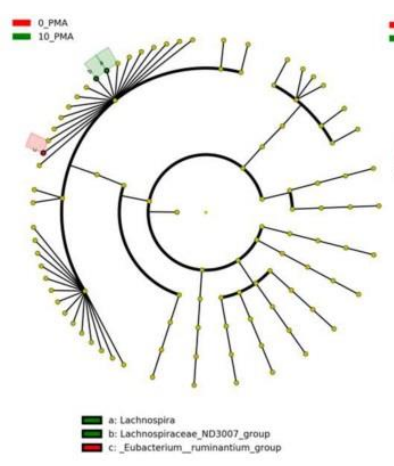
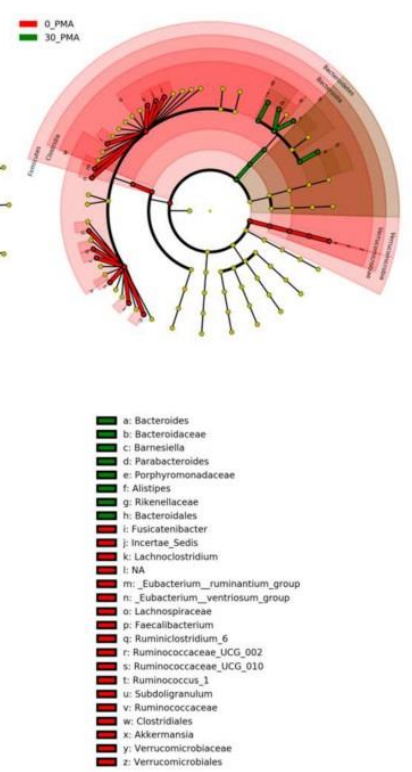
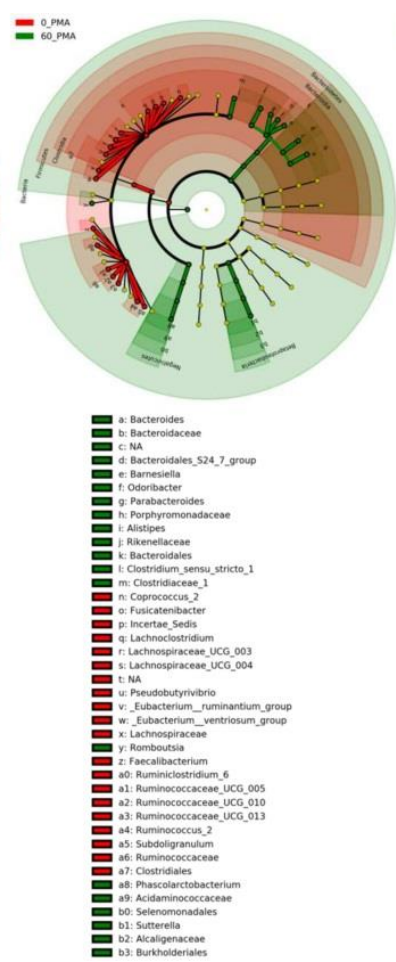
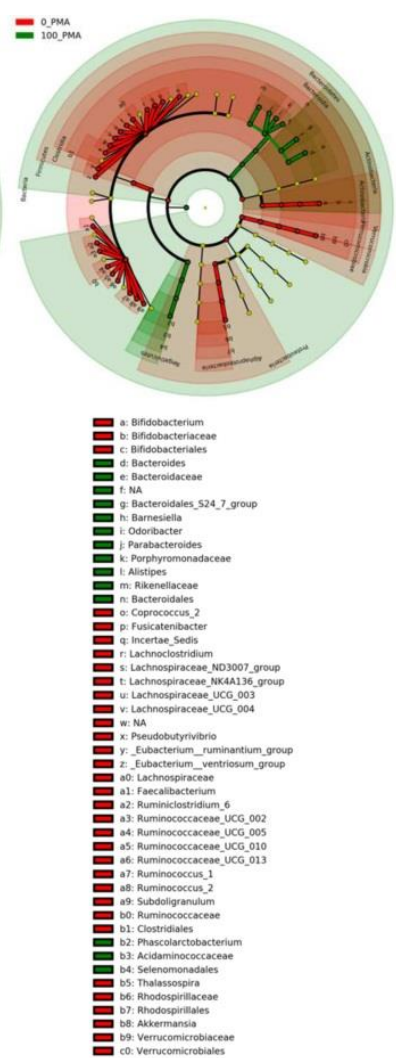

Figure 4. Graphical summary of significantly changed RSVs (100 most abundant, LefSE analyses) in experiment $A$ at concentrations of 10, 30, 60 and $100 \mu M$ PMA. RSVs which increased or decreased in relative abundance after PMA treatment are given in green and red, respectively. Full information on the 100 most relatively abundant identified RSVs and results including PMA concentrations is available in Supplementary Table 1.

In experiment B we tested if increasing the amount of PMA concentration up to $300 \mu \mathrm{M}$ would significantly change the community membership at RSV level. Of 100 most abundant RSVs which were analysed, 68 RSVs changed significantly with PMA treatment. We applied PMA at four different concentrations $(50 \mu \mathrm{M}, 100 \mu \mathrm{M}, 150 \mu \mathrm{M}$, and $300 \mu \mathrm{M})$, and found that 49 RSVs at $50 \mu \mathrm{M}$ PMA concentration, 44 RSVs at $100 \mu \mathrm{M}$ PMA concentration, 43 RSVs at 
bioRxiv preprint doi: https://doi.org/10.1101/343194; this version posted July 10,2018. The copyright holder for this preprint (which was not certified by peer review) is the author/funder, who has granted bioRxiv a license to display the preprint in perpetuity. It is made available under aCC-BY-NC 4.0 International license.

$150 \mu \mathrm{M}$ PMA concentration, and 42 RSVs at $300 \mu \mathrm{M}$ PMA concentration were increased or decreased significantly. Interestingly, for 59 out of 68 RSVs $(87 \%)$ the significant change occurred already at 50 or $100 \mu \mathrm{M}$ PMA, suggesting that using a larger concentration does not substantially affect the community profile on RSV level.

\section{Firmicutes/Bacteroidetes ratio decreased significantly upon PMA treatment}

As detected with LEfSe analysis most of the RSVs belonging to phylum Firmicutes decreased in relative abundance with PMA treatment, and RSVs in phylum Bacteroidetes increased. As Firmicutes/Bacteroidetes ratio in human gut microbiota has been connected to human health and disease, we pursued to look deeper into how the PMA treatment changed this ratio. We found that the Firmicutes/Bacteroidetes ratio decreased by $21 \%$ in experiment $\mathrm{A}$ at a concentration of $30 \mu \mathrm{M}$ PMA (Student's t-test $\mathrm{p}=0.031$ ), and even $31 \%$ at $100 \mu \mathrm{M}$ of PMA (Student's t-test $\mathrm{p}=0.018$ ). In experiment $\mathrm{B}$ the Firmicutes/Bacteroidetes ratio did not further decrease with increasing PMA concentration, but a statistically significant 30-33\% reduction compared to $0 \mu \mathrm{M}$ PMA was observed with all PMA concentrations (t-test $\mathrm{p}$ values range $0.0004-0.04)$ (Figure 5.).

a)

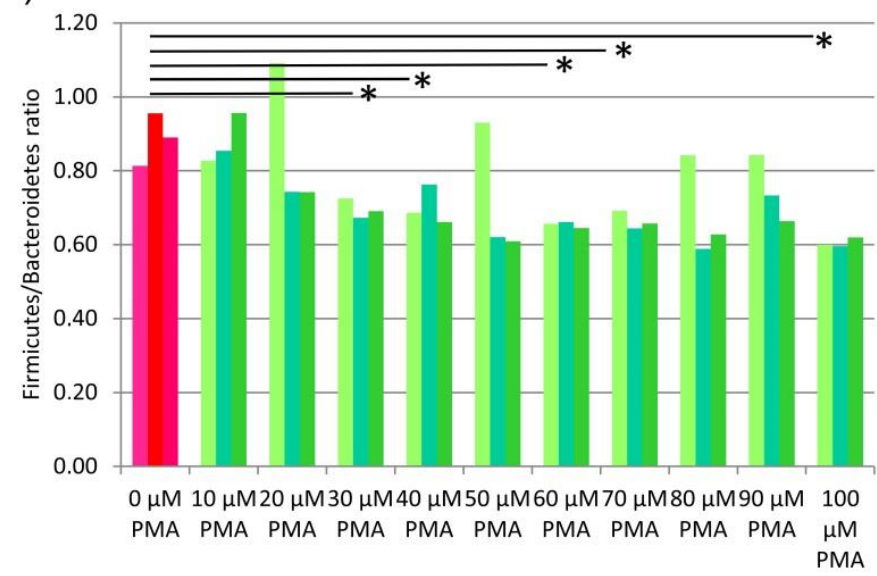

b)

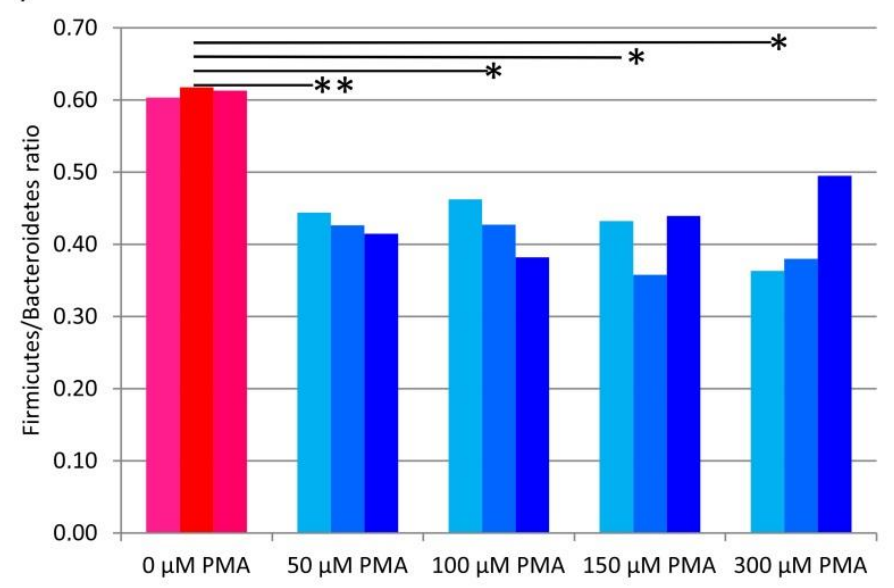

Figure 5. Firmicutes/Bacteroidetes ratio decreased significantly with PMA treatment. a) Experiment A, b) experiment B. The stars above the bars depict the statistical significance of results: when p-value is $<0.05$, it is shown with ${ }^{*}$, and when $p$-value is $<0.01$, it is shown with **. 
bioRxiv preprint doi: https://doi.org/10.1101/343194; this version posted July 10, 2018. The copyright holder for this preprint (which was not certified by peer review) is the author/funder, who has granted bioRxiv a license to display the preprint in perpetuity. It is made available under aCC-BY-NC 4.0 International license.

\section{Discussion}

The purpose of this study was to analyze the correlation of PMA concentration and the microbial composition after NGS in complex biosamples such as stool, with the goal to establish a guideline for future applications.

Most studies using PMA with stool samples were performed with standard PMA concentration of $50 \mu \mathrm{M}$. However, testing the effect of increasing PMA concentrations on stool samples, and determining the relative abundances in correlation with live / dead status of specific microorganisms has not been studied before. Here, we applied Illumina MiSeq sequencing to decipher the effect of PMA treatment on turbid stool samples and their diverse microbial community.

This study revealed that PMA treatment significantly decreases microbial richness and diversity (alpha diversity) and alters the microbial community profile (beta diversity). The magnitude of these effects was found to be concentration dependent. Furthermore, the increase and decrease in relative abundance after PMA treatment was taxon-specific, revealing a significantly different composition of the microbial community when only intact cells were targeted.

A decrease in diversity suggests that either certain taxa totally disappeared (richness), or the evenness decreased when the relative abundances of different taxa shifted upon PMA treatment. In our experiments, the majority of 100 most abundant RSVs either increased or decreased statistically significantly in relative abundance at one or more applied PMA concentrations, but only few RSVs completely disappeared. This suggests that PMA treatment particularly affected the evenness of the microbial community. Furthermore, the change in beta diversity suggests that the community profile shifted upon PMA treatment: certain taxonomic groups became more abundant, some less abundant, and some were not detectable any more. This indicates that they were not intact, but represented in the non PMA treated samples only by fragments of free DNA or DNA within cells with fractured cell walls. Thus, we state that without using any live/dead distinction method, the active and significant microbial diversity in stool might be miscalculated.

The effect of PMA on both alpha and beta diversity was clearly concentration dependent. In particular, the application higher than $100 \mu \mathrm{M}$ PMA showed a significant decrease in the alpha diversity compared to untreated samples. Additionally, the community profile shift was stronger with higher PMA concentrations, suggesting that low PMA concentrations only can mask part of the free DNA or DNA inside fractured cells, because of turbidity.

We observed that the increase and decrease in relative abundance after PMA treatment was taxon specific, revealing a significantly different composition of the microbial community when only intact cells were targeted. Particularly the relative abundance of Firmicutes was significantly reduced and the relative abundance of Bacteroidetes significantly increased when PMA treatment was applied, leading to the conclusion that without any live/dead staining or viability testing the number of Firmicutes might be significantly overestimated while Bacteroidetes are underestimated. In particular, the Firmicutes/Bacteroidetes ratio has been connected to human health in a number of publications ${ }^{34-36}$.

Gram-positive Firmicutes are predominantly associated with energy harvest from diet ${ }^{37,38}$, while Gram-negative Bacteroidetes are known to perform several beneficial processes related to degradation of complex sugars and proteins into short chain fatty acids (SCFAs) ${ }^{39}$, and the 
bioRxiv preprint doi: https://doi.org/101101/343194; this version posted July 10,2018. The copyright holder for this preprint (which was not certified by peer review) is the author/funder, who has granted bioRxiv a license to display the preprint in perpetuity. It is made available under aCC-BY-NC 4.0 International license.

relative proportion of Bacteroidetes has been observed to be decreased in obesity ${ }^{34}$. In the Bacteroidetes phylum, we detected a systematic and significant increase of the genera Bacteroides, Alistipes, and Parabacteroides upon PMA treatment. Bacteroides comprises the most substantial portion of the human gastrointestinal microbial community, and is known to play a fundamental role in processing complex molecules to succinate and acetate (major fermentation products) ${ }^{40}$ in the host intestine ${ }^{41,42}$, and it contributes to the lean phenotype ${ }^{43}$. Alistipes, and Parabacteroides used to belong to genus Bacteroides and thus share many metabolic features, including fermentation of complex sugars, and production of acetic and succinic acids ${ }^{44-46}$.

Within the phylum Firmicutes we observed a systematic decrease of the genus Faecalibacterium, which is one of the most abundant and important commensal bacteria of the human gut microbiota. Faecalibacterium is known to produce butyrate and other shortchain fatty acids through the fermentation of dietary fiber and to boost the immune system. Additionally, relatively low levels of $F$. prausnitzii in human intestines were associated with e.g. inflammatory bowel diseases (Crohn's disease) ${ }^{47}$ and ulcerative colitis ${ }^{48}$, obesity ${ }^{49}$, asthma ${ }^{50}$ and depression ${ }^{51}$.

Besides Faecalibacterium, also other important human gut bacteria were significantly affected by the PMA treatment: the genera Bifidobacterium and Akkermansia both decreased in relative abundance upon PMA treatment. These bacteria are known to carry beneficial properties for human health and their application as probiotics has been extensively studied. For example Bifidobacterium has been connected to beneficial psychological effects ${ }^{52}$ better mental health ${ }^{53}$, and allergy prevention ${ }^{54}$. It is suggested to be effective at protecting against infectious diseases ${ }^{55}$, whereas Akkermansia is known to stimulate immune system, improve gut barrier function ${ }^{56-58}$, and prevent the development of obesity (fat mass development, insulin resistance and dyslipidemia) in mice studies ${ }^{58}$. Additionally, the level of Akkermansia muciniphila was reported to be drastically reduced in patients with Crohn's disease and ulcerative colitis, and suggested to be a health biomarker ${ }^{59}$.

Based on our study, supported by the results of a study aiming at the discrimination of viable and dead fecal Bacteroidales by quantitative PCR ${ }^{60}$, we suggest using a concentration of 100 $\mu \mathrm{M}$ of PMA to efficiently block background DNA from open or broken cells in fecal samples.

Although human faeces samples do not reflect the situation at the respective site within the intestine ${ }^{61,62}$, they are used for numerous microbiome analyses and correlation studies of microbial composition and health or disease. Excluding the background signals by PMA treatment can increase the impact of such studies, as the intact microorganisms might mirror the in situ situation in more detail.

\section{Limitations of the study}

The stool samples were immediately processed and handled in the dark throughout the experiments. However, the samples were exposed to air (21\% oxygen) for a short period of time during dilution and PMA treatment, which might affect the viability of the microbial community ${ }^{2}$. However, we cannot think of any chemical process, which would, in the dark but in presence of air, induce immediate cell wall/cell membrane damage, and thus affect the outcome of the PMA treatment ${ }^{63}$, so that we did not evaluate the impact of the oxygen in the ambient air on our results. In this regard, the study setup was performed according to feasibility and common practice, and the samples were treated with PMA without delay, but under normal atmosphere. 


\section{Conclusion}

Treatment with propidium monoazide is a relatively simple and cheap protocol to exclude background DNA from damaged cells in DNA-based microbiome studies. Herein, we propose to use $100 \mu \mathrm{M}$ PMA for optimal live/dead distinction in stool microbiome analyses, as we identified the standard concentration of $50 \mu \mathrm{M}$ to be less effective in such turbid samples. In our study, we found that the intact, and thus most likely viable fraction of the microbial community, differs significantly from the overall microbial profile. This finding indicates, that many previous studies might have over- or underestimated the importance of key microbial species in gut samples, as they did not consider the live/dead situation of the cells.

\section{Declarations}

Ethics approval and consent to participate

Research involving human material was performed in accordance with the Declaration of Helsinki and was approved by the local ethics committees (the Ethics Committee at the Medical University of Graz, Graz, Austria). Stool samples have been obtained covered by the ethics vote 27-151 ex 14/15.

\section{Consent for publication}

Not applicable.

\section{Availability of data and material}

Sequence data were submitted to the European Nucleotide Archive (ENA) with the study accession number PRJEB25855.

\section{Competing interests}

The authors declare that the research was conducted in the absence of any commercial or financial relationships that could be construed as a potential conflict of interest.

\section{Funding}

This study was supported by the Kulturamt Stadt Graz ("Life-dead analyses with stool microbiomes") and BioTechMed-Graz. MM was trained within the frame of the Ph.D. Program Molecular Medicine of the Medical University of Graz.

\section{Authors' Contributions}

AP, MM, CME conceived and designed the study. AP, MM, MB, LW collected and processed the samples, KK, AP, CME analysed and interpreted the data, and AKP, KK, CME drafted and revised the manuscript. All authors approved the final version of the manuscript.

\section{Acknowledgements}

We thank the City of Graz cultural office, BioTechMed-Graz, and Ph.D. Program Molecular Medicine of the Medical University of Graz for funding.

\section{Additional files}

\section{Additional tables}


bioRxiv preprint doi: https://doi.org/10.1101/343194; this version posted July 10,2018. The copyright holder for this preprint (which was not certified by peer review) is the author/funder, who has granted bioRxiv a license to display the preprint in perpetuity. It is made available under aCC-BY-NC 4.0 International license.

\section{Additional Table 1.}

Microsoft Excel File Format, .xlsx

Description of data: Summary of 100most abundant taxa in Experiment A, and the changes in relative abundance upon PMA treatment. Bacterial taxa (RSVs) that increased are marked in green, and taxa that decreased are marked in red.

\section{Additional Table 2.}

Microsoft Excel File Format, .xlsx

Description of data: Summary of 100most abundant taxa in Experiment B, and the changes in relative abundance upon PMA treatment. Bacterial taxa (RSVs) that increased are marked in green, and taxa that decreased are marked in red.

\section{References}

1. Emerson, J. B. et al. Schrodinger's microbes: Tools for distinguishing the living from the dead in microbial ecosystems. Microbiome. 2017; 5:86-017-0285-3.

2. Chu, N. D., Smith, M. B., Perrotta, A. R., Kassam, Z. \& Alm, E. J. Profiling Living Bacteria Informs Preparation of Fecal Microbiota Transplantations. PLoS One. 2017;12: $\mathrm{e} 0170922$

3. Amann, R. I., Ludwig, W. \& Schleifer, K. H. Phylogenetic identification and in situ detection of individual microbial cells without cultivation. Microbiol. Rev.1995;59:143-169. 4. Stewart, E. J. Growing unculturable bacteria. J. Bacteriol. 2012;194:4151-4160. 5. Ju, W., Moyne, A. L. \& Marco, M. L. RNA-Based Detection Does not Accurately Enumerate Living Escherichia coli O157:H7 Cells on Plants. Front. Microbiol. 2016;7:223. 6. Nocker, A., Cheung, C. Y. \& Camper, A. K. Comparison of propidium monoazide with ethidium monoazide for differentiation of live vs. dead bacteria by selective removal of DNA from dead cells. J. Microbiol. Methods. 20016;67:310-320.

7. Rogers, G. B. et al. Reducing bias in bacterial community analysis of lower respiratory infections. ISME J. 2013;7:697-706.

8. Probst, A. J., Auerbach, A. K. \& Moissl-Eichinger, C. Archaea on human skin. PLoS One. 2013;8:e65388.

9. Cuthbertson, L. et al. Implications of multiple freeze-thawing on respiratory samples for culture-independent analyses. J. Cyst Fibros. 2015;14:464-467.

10. Moissl-Eichinger, C. et al. Quo vadis? Microbial profiling revealed strong effects of cleanroom maintenance and routes of contamination in indoor environments. Sci. Rep. 2015;5:9156.

11. Kibbee, R. J. \& Ormeci, B. Development of a sensitive and false-positive free PMAqPCR viability assay to quantify VBNC Escherichia coli and evaluate disinfection performance in wastewater effluent. J. Microbiol. Methods. 2017;132:139-147.

12. Salter, S. J. et al. Reagent and laboratory contamination can critically impact sequencebased microbiome analyses. BMC Biology. 2014;12:87.

13. Mamlouk, K. et al. Quantification of viable Brochothrix thermosphacta in cooked shrimp and salmon by real-time PCR. Food Microbiol. 2012;30:173-179.

14. Elizaquivel, P., Sanchez, G. \& Aznar, R. Application of propidium monoazide quantitative PCR for selective detection of live Escherichia coli O157:H7 in vegetables after inactivation by essential oils. Int. J. Food Microbiol. 2012;159:115-121.

15. Lee, H. W., Lee, H. M., Yoon, S. R., Kim, S. H. \& Ha, J. H. Pretreatment with propidium monoazide/sodium lauroyl sarcosinate improves discrimination of infectious waterborne virus by RT-qPCR combined with magnetic separation. Environ. Pollut. 2018;233:306-314. 
bioRxiv preprint doi: https://doi.org/10.1101/343194; this version posted July 10, 2018. The copyright holder for this preprint (which was not certified by peer review) is the author/funder, who has granted bioRxiv a license to display the preprint in perpetuity. It is made available under aCC-BY-NC 4.0 International license.

16. Scariot, M. C., Venturelli, G. L., Prudencio, E. S. \& Arisi, A. C. M. Quantification of Lactobacillus paracasei viable cells in probiotic yoghurt by propidium monoazide combined with quantitative PCR. Int. J. Food Microbiol. 2018;264:1-7.

17. Tantikachornkiat, M., Sakakibara, S., Neuner, M. \& Durall, D. M. The use of propidium monoazide in conjunction with qPCR and Illumina sequencing to identify and quantify live yeasts and bacteria. Int. J. Food Microbiol. 2016;234:53-59.

18. Weinmaier, T. et al. A viability-linked metagenomic analysis of cleanroom environments: eukarya, prokaryotes, and viruses. Microbiome. 2015;3:62-015-0129-y.

19. Mohapatra, B. R. \& La Duc, M. T. Rapid detection of viable Bacillus pumilus SAFR-032 encapsulated spores using novel propidium monoazide-linked fluorescence in situ hybridization. J. Microbiol. Methods. 2012;90:15-19.

20. Probst, A., Mahnert, A., Weber, C., Haberer, K. \& Moissl-Eichinger, C. Detecting inactivated endospores in fluorescence microscopy using propidium monoazide. International Journal of Astrobiology. 2012;11:117-123.

21. Nocker, A., Mazza, A., Masson, L., Camper, A. K. \& Brousseau, R. Selective detection of live bacteria combining propidium monoazide sample treatment with microarray technology. J. Microbiol. Methods. 2009;76:253-261.

22. Nocker, A., Sossa-Fernandez, P., Burr, M. D. \& Camper, A. K. Use of propidium monoazide for live/dead distinction in microbial ecology. Appl. Environ. Microbiol. 2007;73:5111-5117.

23. Fittipaldi, M., Nocker, A. \& Codony, F. Progress in understanding preferential detection of live cells using viability dyes in combination with DNA amplification. J. Microbiol. Methods. 2012;91:276-289.

24. Heise, J., Nega, M., Alawi, M. \& Wagner, D. Propidium monoazide treatment to distinguish between live and dead methanogens in pure cultures and environmental samples. J. Microbiol. Methods. 2016;121:11-23.

25. Pferschy-Wenzig, E. M., Koskinen, K., Moissl-Eichinger, C. \& Bauer, R. A Combined LC-MS Metabolomics- and 16S rRNA Sequencing Platform to Assess Interactions between Herbal Medicinal Products and Human Gut Bacteria in Vitro: a Pilot Study on Willow Bark Extract. Front. Pharmacol. 2017;8:893.

26. Young, G. R. et al. Reducing Viability Bias in Analysis of Gut Microbiota in Preterm Infants at Risk of NEC and Sepsis. Front. Cell. Infect. Microbiol. 2017;7:237.

27. Caporaso, J. G. et al. Ultra-high-throughput microbial community analysis on the Illumina HiSeq and MiSeq platforms. ISME J. 2012;6:1621-1624.

28. Callahan, B. J. et al. DADA2: High-resolution sample inference from Illumina amplicon data. Nat. Methods. 2016;13:581-583.

29. Quast, C. et al. The SILVA ribosomal RNA gene database project: improved data processing and web-based tools. Nucleic Acids Res. 2013;41:D590-6.

30. R Development Core Team. A language and environment for statistical computing. $R$ Foundation for Statistical Computing. Vienna, Austria. ISBN 3-900051-07-0, URL http://www.R-project.org 2008.

31. McMurdie, P. J. \& Holmes, S. phyloseq: an R package for reproducible interactive analysis and graphics of microbiome census data. PLoS One. 2013;8:e61217.

32. Oksanen, J. et al. Vegan: community ecology package. R package version 2.0-7. https://github.com/vegandevs/vegan 2016.

33. Segata, N. et al. Metagenomic biomarker discovery and explanation. Genome Biol. 2011;12:R60-2011-12-6-r60.

34. Ley, R. E., Turnbaugh, P. J., Klein, S. \& Gordon, J. I. Microbial ecology: human gut microbes associated with obesity. Nature. 2006;444:1022-1023.

35. Koliada, A. et al. Association between body mass index and Firmicutes/Bacteroidetes ratio in an adult Ukrainian population. BMC Microbiol. 2017;17:120-017-1027-1. 
bioRxiv preprint doi: https://doi.org/10.1101/343194; this version posted July 10, 2018. The copyright holder for this preprint (which was not certified by peer review) is the author/funder, who has granted bioRxiv a license to display the preprint in perpetuity. It is made available under aCC-BY-NC 4.0 International license.

36. Mariat, D. et al. The Firmicutes/Bacteroidetes ratio of the human microbiota changes with age. BMC Microbiol. 2009;9:123-2180-9-123.

37. Turnbaugh, P. J. et al. An obesity-associated gut microbiome with increased capacity for energy harvest. Nature. 2006;444:1027-1031.

38. Murphy, E. F. et al. Composition and energy harvesting capacity of the gut microbiota: relationship to diet, obesity and time in mouse models. Gut. 2010;59:1635-1642.

39. Thomas, F., Hehemann, J. H., Rebuffet, E., Czjzek, M. \& Michel, G. Environmental and gut bacteroidetes: the food connection. Front. Microbiol. 2011;2:93.

40. Song, Y., Chengxu, L. \& Finegold, S. M. Bacteroides. Bergey's Manual of Systematics of Archaea and Bacteria 2015.

41. Wexler, H. M. Bacteroides: the good, the bad, and the nitty-gritty. Clin. Microbiol. Rev.2007;20:593-621.

42. $\mathrm{Xu}, \mathrm{J}$. et al. Evolution of symbiotic bacteria in the distal human intestine. PLoS Biol. 2007;5:e156.

43. Ridaura, V. K. et al. Gut microbiota from twins discordant for obesity modulate metabolism in mice. Science. 2013;341:1241214.

44. Sakamoto, M. \& Benno, Y. Reclassification of Bacteroides distasonis, Bacteroides goldsteinii and Bacteroides merdae as Parabacteroides distasonis gen. nov., comb. nov., Parabacteroides goldsteinii comb. nov. and Parabacteroides merdae comb. nov. Int. J. Syst. Evol. Microbiol. 2006;56:1599-1605.

45. Könönen Eija, Yuli, S., Merja, R. \& Finegold, S. M. Alistipes. Bergey's Manual of Systematics of Archaea and Bacteria 2015.

46. Rautio, M. et al. Reclassification of Bacteroides putredinis (Weinberg et al., 1937) in a new genus Alistipes gen. nov., as Alistipes putredinis comb. nov., and description of Alistipes finegoldii sp. nov., from human sources. Syst. Appl. Microbiol. 2003;26:182-188.

47. Sokol, H. et al. Faecalibacterium prausnitzii is an anti-inflammatory commensal bacterium identified by gut microbiota analysis of Crohn disease patients. Proc. Natl. Acad. Sci. U. S. A. 2008;105:16731-16736.

48. Varela, E. et al. Colonisation by Faecalibacterium prausnitzii and maintenance of clinical remission in patients with ulcerative colitis. Aliment. Pharmacol. Ther. 2013;38:151-161.

49. Hippe, B. et al. Faecalibacterium prausnitzii phylotypes in type two diabetic, obese, and lean control subjects. Benef Microbes. 2016;7:511-517.

50. Stokholm, J. et al. Maturation of the gut microbiome and risk of asthma in childhood. Nat. Commun. 2018;9:141-017-02573-2.

51. Jiang, H. et al. Altered fecal microbiota composition in patients with major depressive disorder. Brain Behav. Immun. 2015;48:186-194.

52. Messaoudi, M. et al. Beneficial psychological effects of a probiotic formulation (Lactobacillus helveticus R0052 and Bifidobacterium longum R0175) in healthy human volunteers. Gut Microbes. 2011;2:256-261.

53. Pinto-Sanchez, M. I. et al. Probiotic Bifidobacterium longum NCC3001 Reduces Depression Scores and Alters Brain Activity: A Pilot Study in Patients With Irritable Bowel Syndrome. Gastroenterology. 2017;153:448-459.e8.

54. Ouwehand, A. C. Antiallergic effects of probiotics. J. Nutr. 2007;137:794S-7S.

55. O'Mahony, D. et al. Bifidobacterium animalis AHC7 protects against pathogen-induced

NF-kappaB activation in vivo. BMC Immunol. 2010;11:63-2172-11-63.

56. Derrien, M., Vaughan, E. E., Plugge, C. M. \& de Vos, W. M. Akkermansia muciniphila gen. nov., sp. nov., a human intestinal mucin-degrading bacterium. Int. J. Syst. Evol.

Microbiol. 2004;54:1469-1476.

57. Derrien, M. et al. Modulation of Mucosal Immune Response, Tolerance, and Proliferation in Mice Colonized by the Mucin-Degrader Akkermansia muciniphila. Front. Microbiol.

2011;2:166. 
58. Plovier, H. et al. A purified membrane protein from Akkermansia muciniphila or the pasteurized bacterium improves metabolism in obese and diabetic mice. Nat. Med. 2017;23:107-113.

59. Png, C. W. et al. Mucolytic bacteria with increased prevalence in IBD mucosa augment in vitro utilization of mucin by other bacteria. Am. J. Gastroenterol. 2010;105:2420-2428.

60. Bae, S. \& Wuertz, S. Discrimination of viable and dead fecal Bacteroidales bacteria by quantitative PCR with propidium monoazide. Appl. Environ. Microbiol. 2009;75:2940-2944. 61. Gorkiewicz, G. et al. Alterations in the colonic microbiota in response to osmotic diarrhea. PLoS One. 2013;8:e55817.

62. Bashir, M. et al. Effects of high doses of vitamin D3 on mucosa-associated gut microbiome vary between regions of the human gastrointestinal tract. Eur. J. Nutr. 2016;55:1479-1489.

63. McClary, J. S., Sassoubre, L. M. \& Boehm, A. B. Staphylococcus aureus Strain Newman Photoinactivation and Cellular Response to Sunlight Exposure. Appl. Environ. Microbiol.

2017;83:10.1128/AEM.01052-17. 